\title{
Pemberdayaan Masyarakat dalam Pengelolaan Limbah Terasi di Pesisir Selatan Jember
}

\author{
Community Empowerment in The Management ff Terasi Waste in the Selatan Coast of Jember
}

\author{
Awatiful Azza ${ }^{1 *}$, Diyan Indriyani ${ }^{1}$, Ika Priantari ${ }^{2}$ \\ ${ }^{1}$ Jurusan Keperawatan Universitas Muhammadiyah Jember \\ ${ }^{2}$ Jurusan Biologi Universitas Muhammadiyah Jember \\ *awatiful.azza@unmuhjember.ac.id
}

\section{ABSTRAK}

Tingginya minat masyarakat akan terasi Puger ini menyebabkan industri rumah tangga ini harus meningkatkan jumlah produksinya. Hal tersebut berdampak pada banyaknya limbah home industry yang tidak diperhatikan pembuangannya, serta berkurangnya kualitas hygiene dari produk terasi. Mitra merupakan pengelola home industri terasi Puger yaitu UD Dua Berlian dan Kelurahan Puger Kulon Kabupaten Jember. Tujuan utama dari pelaksanaan program KKN-PPM yang berjudul "Pemberdayaan Masyarakat Dalam Pengelolaan Limbah Terasi Di Pesisir Selatan Jember" ini adalah untuk mengatasi permasalahan Mitra berupa: 1) belum optimalnya pemahaman Mitra tentang hidup bersih dan sehat., 2) belum optimalnya pemahaman Mitra tentang teknik pemasaran dan pengemasan terasi yang hygienis, 3) kurangnya keterampilan masyarakat dalam mengelola limbah terasi, sehingga beresiko mencemari lingkungan. Solusi untuk permasalahan yang dihadapi Mitra tersebut, perlu dilakukan tindakan berupa: 1) melakukan kerja bakti bersama dalam membersihkan lingkungan tempat pelelangan ikan, 2) melakukan pelatihan pengelolaan limbah terasi menjdi pupuk organik cair, 3) pelatihan penggunaan pupuk organik cair untuk penghijauan, 4) pelatihan pemasaran dan pengemasan produk terasi 5) penyuluhan tentang perilaku hidup bersih dan sehat 6) pemberdayaan masyarakat dalam penggunaan pupuk organik cair di lahan.. Selanjutnya target kegiatan ini adalah pengelola home indutri terasi mampu menjaga kebersihan tempat pembuatan terasi dan lebih hygienis. Mampu memanfaatkan limbah terasi untuk pupuk organik cair yang dapat meningkatkan kesuburan tanah pesisir. Jangka waktu pelaksanaan kegiatan PKM ini selama 2 bulan dengan melibatkan mahasiswa KKN sebanyak 20 mahasiswa . Metode pendekatan yang ditawarkan untuk menyelesaikan persoalan mitra program KKN-PPM adalah Pengelola terasi Puger mampu mengelola limbah menjadi pupuk organik cair dengan tahapan pelaksanaan sebagai berikut: 1) Persiapan dan pembekalan meliputi : (a) koordinasi dengan sasaran program KKN-PPM yaitu Kelurahan Puger Kulon, Kecamatan Puger, Kabupaten Jember, (b) Koordinasi dengan calon Mitra KKN-PPM (UD Berlian, pengelola home industry terasi Puger dan Pemerintah Desa Puger Kulon, Kecamatan Puger, Kabupaten Jember), (c) Sosialisasi Program KKN-PPM kepada mahasiswa sebagai calon peserta Program KKN-PPM (d) Pelatihan pembuatan Pupuk organik cair, (e) pelatihan tehnik pemasaran,(f) Penyuluhan tentang perilaku hidup bersih dan sehat. Dengan Volume pekerjaan dalam bentuk Jam Kerja Efektif Mahasiswa (JKEM) selama kegiatan adalah 147 JKEM.
\end{abstract}

Kata Kunci: Pemberdayaan masyarakat, Limbah terasi, pupuk organik cair

\begin{abstract}
The high public interest in this puger shrimp paste has caused this home industry to increase the amount of its production. This has an impact on the amount of home industry waste that is not properly disposed of, as well as the reduced hygiene quality of shrimp paste products. Mitra is the manager of the Puger shrimp paste home industry, namely UD Dua Berlian and Puger Kulon Village, Jember Regency. The main objective of the implementation of the KKN-PPM program entitled "Community Empowerment in Waste Management of Terasi Selatan Jember" is to overcome Partner's problems in the form of: 1) Partner's understanding of clean and healthy living is not yet optimal. hygienic marketing and packaging techniques for shrimp paste, 3) lack of community skills in managing shrimp paste waste, so there is a risk of polluting the environment. The solution to the problems faced by the Partners, it is necessary to take actions in the form of: 1) doing community service in cleaning the environment where fish auctions are located, 2) conducting training on the management of shrimp paste waste into liquid organic fertilizer, 3) training on the use of liquid organic fertilizer for reforestation, 4) training on marketing and packaging of shrimp paste products 5) counseling on clean and healthy living behavior 6) community empowerment in the use of liquid organic fertilizer in the field. Furthermore, the target of this activity is that the home industry manager for shrimp paste is able to maintain the cleanliness of the shrimp paste making place and is more hygienic. Able to utilize shrimp paste waste for liquid organic fertilizer which can increase coastal soil fertility. The implementation period of this PKM activity is 2 months, involving 20 KKN students. The approach method offered to solve the problems of the KKN-PPM program partners is that the Puger shrimp paste manager is able to manage waste into liquid organic fertilizer with the following implementation stages: 1) Preparation and debriefing include: (a) coordination with the target of the KKN-PPM program, namely Puger Kulon Village, Puger District, Jember Regency, (b) Coordination with prospective KKN-PPM Partners (UD Berlian, manager of the Puger shrimp paste home industry and Puger Kulon Village Government, Puger District, Jember Regency), (c) Socialization of the KKN-PPM Program to students as prospective participants of the KKN-PPM Program (d) Training on making liquid organic fertilizer, (e) training on marketing techniques, (f) Counseling on clean and healthy living behavior. The volume of work in the form of Student Effective Working Hours (JKEM) during the activity is 147 JKEM.
\end{abstract}

Keywords: Community empowerment, shrimp paste waste, liquid organic fertilizer 


\section{Pendahuluan}

\subsection{Potensi Unggulan dan Masalah di Masyarakat}

Keberagaman masyarakat Puger tentunya dapat menjadi aset maupun problem antar budaya, apabila tidak ditangani dengan baik. Home industry terasi di Puger Kulon merupakan salah satu bentuk kewirausahaan yang berbasis masyarakat dengan mengembangkan potensi lokal, baik hasil alam maupun penduduk.

Puger memiliki tempat pelelangan ikan (TPI) terbesar di Kabupaten Jember, namun kondisi TPI ini masih sangat kotor, banyak sampah berserakan, panas dan berbau. Data hasil survey lapangan menunjukkan bahwa tingkat kesadaran masyarakat akan kebersihan lingkungan sangat rendah. Hal tersebut ditunjukkan dengan tidak adanya fasilitas umum tempat sampah yang memadai di seluruh wilayah Puger, di tempat pelelangan ikan dan di tempat pengolahan ikan. Selain itu limbah hasil laut yang berbau menyengat.

Beberapa kegiatan awal yang telah dilaksanakan untuk mendukung pengembangan kewirausahaan berbasis masyarakat Antara lain: penyuluhan masyarakat tentang lingkungan, pelatihan, pengolahan terasi dan penelitian tentang kebijakan.

\subsection{Pemberdayaan Masyarakat Untuk Menyelesaikan Permasalahan}

Berdasarkan permasalahan yang dihadapi oleh masyarakat pengrajin terasi yang ada di desa Puger Kulon Kecamatan Puger tersebut maka Tim LPPM Universitas Muhammadiyah Jember telah menyelenggarakan kegiatan KKN-PPM di wilayah tersebut dengan melibatkan Pemerintah Desa Puger Kulon, dua (2) dosen pembimbing dan 20 mahasiswa yang terdiri dari beberapa disiplin ilmu di UM Jember. Dengan mempertimbangkan permasalahan yang terjadi di Puger Kulon tersebut maka akan lebih mudah diatasi dengan melibatkan beberapa disiplin ilmu, sehingga permasalahan tentang limbah terasi dan penghijauan di wilayah tersebut dapat perlahan teratasi.

Permasalahan yang dihadapi oleh masyarakat Puger Kulon membutuhkan kolaborasi dan kerjasama dari seluruh pihak baik dari akademisi maupun melibatkan dan memberdayakan masyarakat secara langsung. Bentuk pemberdayaan masyarakat yang dilakukan adalah sebagai berikut : 1) Pelatihan pembuatan media pengelolaan limbah industri rumah tangga yang ramah lingkungan, Untuk mengajak masyarakat dan akademisi dalam memberikan jalan keluar terhadap pengelolaan limbah dari produk terasi. Pelatihan yang akan dilakukan untuk mengolah limbah cair terasi adalah pengolahan menjadi pupuk organik cair. 2) Pelatihan dan pendampingan teknik pengemasan terasi secara hygienis, 3) Penyuluhan tentang masyarakat sadar lingkungan dan Gotong royong kerja bakti di TPI (tempat pelelangan ikan), 4) Pelatihan dan bimbingan tentang manajemen bisnis dan pemasaran

\section{Metodologi}

Tahapan Pelaksanaan program KKN-PPM ini adalah sebagai berikut:

\subsection{Persiapan dan Pembekalan}

a. Koordinasi dengan calon sasaran program KKN-PPM yaitu kelompok masyarakat Puger Kulon, Kabupaten Jember.

b. Koordinasi dengan calon Mitra KKN-PPM ( UD Dua Berlian) Desa Puger Kulon, Kecamatan Puger, Kabupaten Jember).

c. Sosialisasi Program KKN-PPM kepada mahasiswa sebagai calon peserta Program KKN-PPM.

d. Pendaftaran dan seleksi mahasiswa sebagai calon peserta Program KKN-PPM.

e. Pembekalan KKN-PPM kepada mahasiswa peserta Program KKN-PPM.

f. Penerjunan mahasiswa peserta Program KKN-PPM ke lokasi.

g. Penyusunan program KKN-PPM dengan masyarakat dan Pemerintah Desa.

h. Pelaksanaan kegiatan KKN-PPM.

i. Monitoring dan evaluasi oleh LPPM Unmuh Jember

j. Laporan kemajuan, seminar, dan laporan akhir.

k. Penutupan KKN-PPM dan Ujian KKN. 


\subsection{Pelaksanaan}

Langkah-langkah dalam bentuk program yang dilaksanakan untuk mencapai hasil yang diharapkan dari tema KKN-PPM yaitu:

a. sharing manajemen bisnis dan pemasaran

b. Penyuluhan dan koordinasi pada kelompok masyarakat.

c. Pelatihan dan sharing pengelolaan limbah terasi menjadi pupuk organik cair

d. Pelatihan Pendampingan pada kelompok masyarakat dalam rangka peningkatan kualitas dan kuantitas produksi dan olahan.

e. Evaluasi secara berkelanjutan terhadap kemajuan yang diperoleh.

\subsection{Monitoring dan Evaluasi}

\subsubsection{Evaluasi Proses,}

merupakan evaluasi yang dilakukan selama proses kegiatan berlangsung. Evaluasi dilakukan mulai tahap awal penjajakan dengan mitra hingga pelaksanaan kegiatan bersama mitra.

\subsubsection{Evaluasi hasil Kegiatan,}

Evaluasi hasil kegiatan ini untuk mendapatkan gambaran ketercapaian program KKN-PPM yang meliputi: pemahaman pengelola terasi Puger meningkat tentang pengolahan limbah terasi, pengolahan terasi secara hygienis dan pemahaman tentang teknik pemasaran. Selain itu Mitra juga mengalami peningkatan keterampilannya dalam mengolah limbah terasi menjadi pupuk organik cair, serta memanfaatkan pupuk untuk penghijauan tanah pesisir.

\subsubsection{Evaluasi dampak kegiatan}

Bertujuan untuk melihat efek kegiatan ini bagi masyarakat secara luas.

Kegiatan monitoring dan evaluasi ini juga dilakukan oleh oleh LPPM Unmuh Jember, Mitra (Pemerintah Desa Puger Kulon,), dan Ditlitabmas, Dikti.

\section{Pembahasan}

\subsection{Hasil}

Kegiatan KKN-PPM ini difokuskan pada pengelola terasi Puger yang ada di di wilayah desa Puger Kulon Kecamatan Puger Kabupaten Jember dengan masalah utama adalah limbah terasi. Adapun kegiatannya dilaksanakan sebagai berikut:

\subsubsection{Persiapan dan Perijinan}

Pada tahapan ini tim KKN-PPM melakukan persiapan secara teknis dan operasional agar mudah dalam proses pelaksanaannya. Hal ini dilakukan dengan cara koordinasi dengan Ketua LPPM Universitas Muhammadiyah Jember. Selain hal tersebut Tim Pelaksana juga melengkapi segala hal yang berkaitan dengan kelengkapan literatur guna menunjang dalam proses implementasi program. Tim pelaksana meminta ijin untuk pelaksanaan KKN-PPM dengan mengajukan permohonan ijin dari Fakultas Ilmu Kesehatan (tanggal 10 Mei 2019) ke Bakesbangpol Kabupaten Jember. Berdasarkan surat ijin dari Bakesbangpol yang telah didapatkan yaitu tanggal 14 Mei 2019 tim Pelaksana melanjutkan rekomendasi ijin ke Kelurahan Puger Kulon Kabupaten Jember.

\subsubsection{Pelaksanaan dan koordinasi}

Tim melakukan Koordinasi dengan kelurahan Puger Kulon dan Mitra I, Serta TPI dan pelabuhan Puger Kulon untuk pelaksanaan program KKN-PPM. Adapun tahapan pelaksanaan program KKN-PPM ini adalah:

a. Kegiatan Pembekalan KKN - PPM

Pembekalan KKN - PPM oleh LPPM Universitas Muhammadiyah Jember telah dilakukan selama 2 hari, yaitu tanggal 23 dan 24 Juli 2019 dengan materi inti :

1) Materi umum meliputi:

- Tata tertib dalam pelaksanaan KKNPPM.

- Penyiapan mental dan psikologis mahasiswa.

- Teori komunikasi massa.

- Kerjasama kelompok dan dinamika masyarakat. 
- Tata tertib dan Undang-undang Pemerintah.

2) Materi khusus meliputi :

- Pemberdayaan ekonomi masyarakat.

- Pemberdayaan masyarakat dalam meningkatkan kemauan dan kemampuan baca

- Perbaikan administrasi lembaga desa.

- Pengelolaan limbah menjadi pupuk organik cair yang bisa meningkatkan ekonomi masyarakat

- Manajemen pemasaran hasil produksi home industry di pesisir pantai selatan Jember

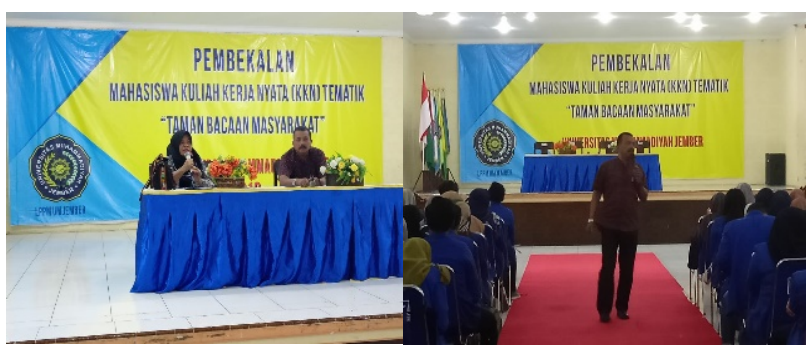

Figure 1. Pembekalan KKN-PPM Mahasiswa Universitas Muhammadiyah Jember

b. Kegiatan Survey, Pendataan Dan Koordinasi Dengan Kelompok Pengelola terasi Puger

Kegiatan survey dan koordinasi kegiatan KKN-PPM Universitas Muhammadiyah Jember 2019 dilakukan dengan melibatkan pihak kelurahan, masyarakat dan pelabuhan Puger yang meliputi:

1) Survey dengan pengelola home industry terasi.

Survey KKN-PPM ini dilakukan dengan mahasiswa yang pelaksanaannya dilakukan sebelum penerjunan mahasiswa KKN ke kelurahan Puger Kulon. Kegiatan survey ini sangat penting, karena dapat menjajaki kebutuhan mitra serta mengetahui sejauh mana mitra memahami tentang permasalahannya, terutama tentang limbah terasi. Mitra sangat antusias dengan program yang dijelaskan oleh team. Karena selama ini semua pengelola terasi belum pernah memanfaatkan limbah untuk dijadikan bahan yang mampu digunakan lagi. Hasil survey di tempat pelelangan ikan, sebagai tempat bahan dasar terasi juga didapatkan banyaknya sampah, lingkungan yang kotor dan kumuh serta bau yang menyengat.

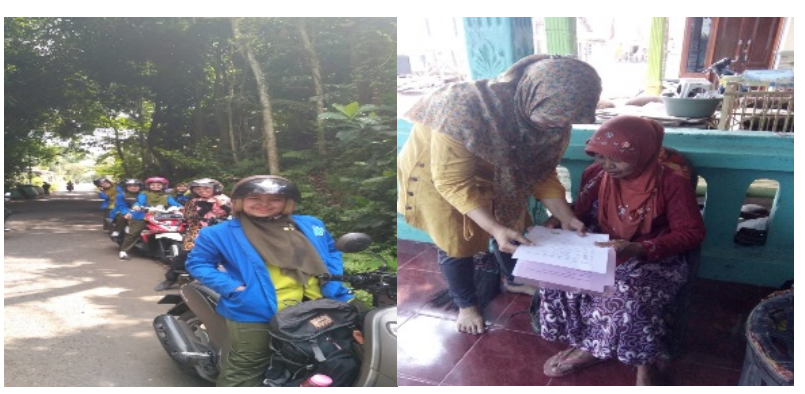

Figure 2. Survey wilayah sasaran dengan lokasi di Puger Kulon

2) Survey dan koordinasi dengan pelabuhan dan tempat pelelangan ikan di Puger

Kegiatan survey ini bertujuan untuk mempersiapkan pelaksanaan program kegiatan kerja bakti dan bersih-bersih antara mahasiswa KKN dan warga dilingkungan Tempat pelelangan ikan Puger dan pelabuhan. Pihak pelabuhan dan tempat pelelangan ikan sangat antusias menyambut program ini, karena menyadarkan masyarakat sekitar sangat sulit kalau hanya dari pelabuhan dan tempat pelelangan ikan Team pelaksana KKN-PPM UM Jember didampingi oleh ketua pelabuhan Puger dan koordinator tempat pelelangan ikan bersama-sama memantau kondisi sampah yang ada di TPI dan pelabuhan Puger

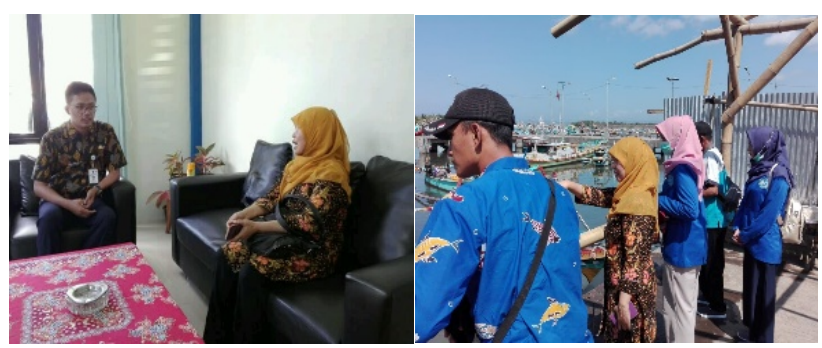

Figure 3. Survey dan koordinasi dengan pihak Pelabuhan dan Tempat Pelelangan Ikan lokasi di Puger Kulon

3) Koordinasi dengan Kepala Desa dan kelompok pengelola home industry terasi Puger pada penyusunan program kerja KKN-PPM.

Pendataan dan koordinasi dengan mitra terkait dengan Dari hasil survey pendataan dan koordinasi dengan mitra, selanjutnya disusun beberapa program 
kegiatan berkaitan dengan pemberdayaan masyarakat melalui :

- Pembentukan kelompok wanita pengelola terasi Puger

- Diskusi pengelolaan limbah terasi menjadi pupuk organik cair

- Pembuatan media untuk tanaman organik dengan menggunakan media tanam hidro aquaponik

- Pelatihan pengolahan limbah udang menjadi pupuk organik cair

- Pelatihan penggunaan pupuk organik cair untuk media tanam hidro Aquaponik

- Kerja Bakti kebersihan untuk tempat pelelangan ikan di Puger serta Pelabuhan Puger

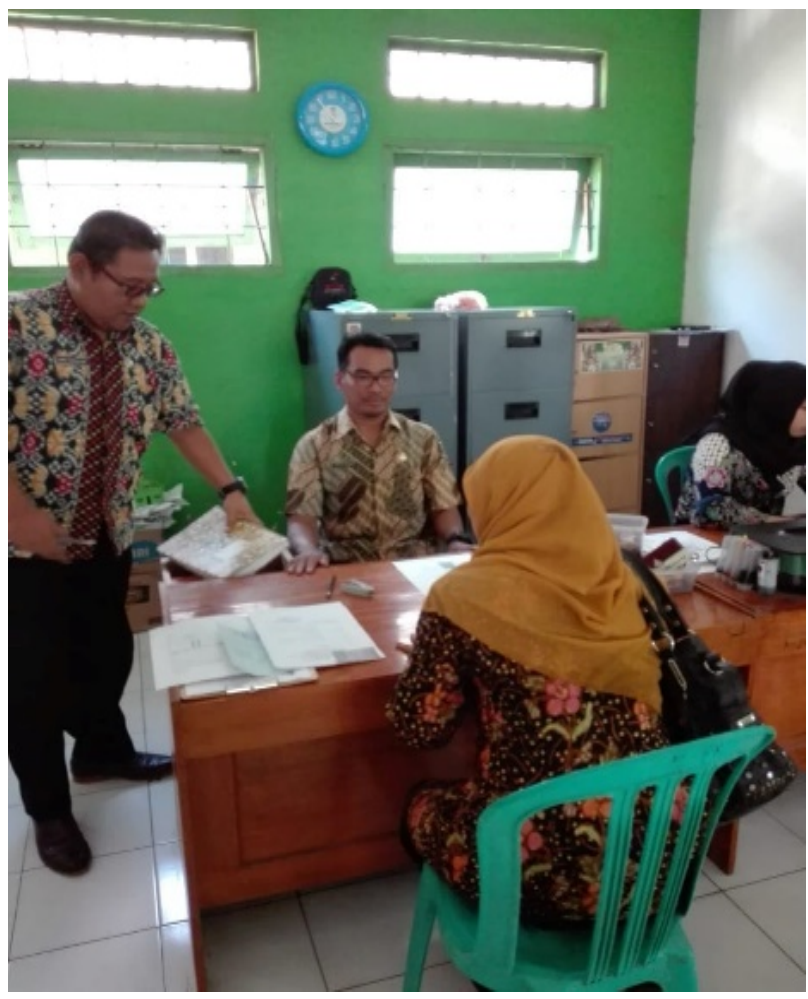

Figure 4. Survey dan koordinasi dengan pihak Kelurahan Puger Kulon dan Puskesmas Puger

c. Pelaksanaan program Kerja Bakti di Tempat Pelelangan Ikan dan Pelabuhan Puger

Kegiatan ini merupakan langkah awal pelaksanaan program KKN-PPM dengan melibatkan mahasiswa KKN dan warga yang ada di sekitar TPI dan Pelabuhan yang dilaksanakan pada 21 Juli 2019. Melalui kegiatan ini salah satu tujuan utamanya adalah memberikan contoh dan mengajarkan langsung tentang perilaku hidup bersih dan sehat pada masyarakat. Masyarakat Puger Kulon sebagian bersuku Madura dengan karakter yang kuat. Kegiatan ini mampu mengajak masyarakat untuk peduli pada lingkungan. Dan stimulasi ini tentunya harus dipupuk terus oleh tokoh masyarakat maupun pengelola pelabuhan Puger, agar masyarakat sadar tentang bahaya sampah bagi lingkungan.

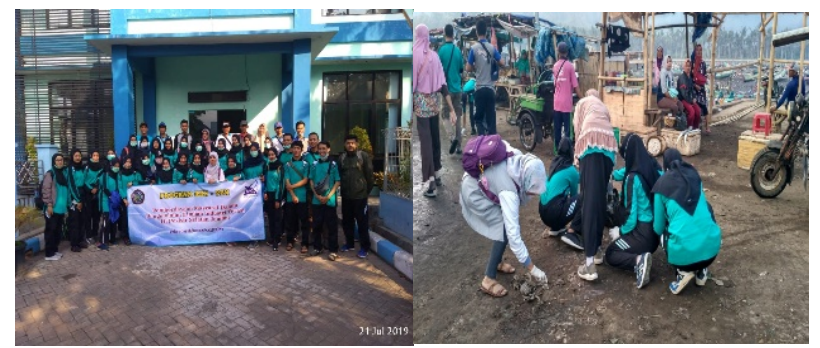

Figure 5. Pelaksanaan program Kerja Bakti di Tempat Pelelangan Ikan dan Pelabuhan Puger

\subsubsection{Koordinasi dengan mahasiswa KKN di Puger Kulon}

Kegiatan ini bertujuan untuk menyiapkan mahasiswa dalam melakukan program lanjutan KKN-PPM dengan membentuk kader penghijauan di desa Puger Kulon.

Mahasiswa KKN cukup antusias dengan program KKN yang akan di kembangkan bersama dengan masyarakat. Pembentukan kader penghijauan kelurahan Puger kulon juga menjadi indikator keberhasilan program KKN ini. Bersama-sama dengan masyarakat banyak program yang sudah dilakukan oleh mahasiswa KKN dengan melibatkan tenaga dan pemikiran bersama warga sekitar.

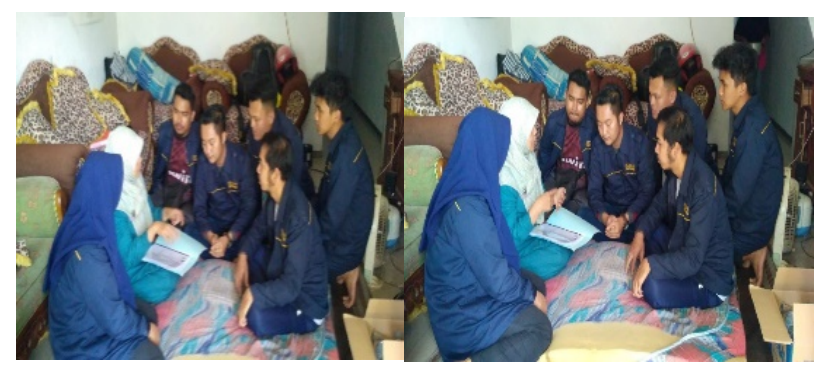

Figure 6. Koordinasi dengan mahasiswa KKN di Puger Kulon

\subsubsection{Koordinasi dengan lab pertanian}

Proses pembuatan pupuk organik cair harus melalui telaah yang tepat, agar produk yang dihasilkan mampu dimanfaatkan untuk 
proses kesuburan tanah. Karakter tanah pesisir yang panas membutuhkan formula khusus agar tanaman yang ditanam di daerah tersebut mampu tumbuh subur dan dapat menghijaukan kelurahan Puger Kulon. Team KKN-PPM selalu berkoordinasi dengan lab pertanian dan lab biologi dasar untuk memaksimalkan pembuatan pupuk organik air dari limbah terasi sebelum melakukan pelatihan dengan mitra

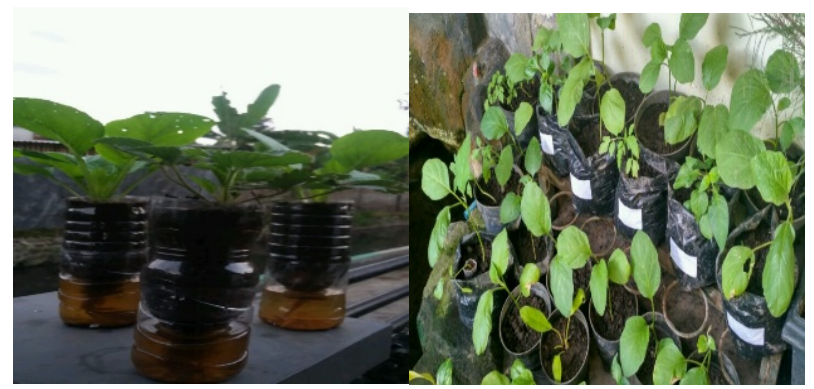

Figure 7. Menyiapkan media tanam dan pengolahan pupuk organik cair

\subsubsection{Pelatihan pembuatan pupuk organik cair}

Kegiatan ini melibatkan 2 mitra yaitu pemerintahan desa Puger kulon dan mitra pengelola home industry terasi dilaksanakan di dua kelompok mitra yang berbeda dengan dilaksanakan 2 kali pelatihan pada mitra satu dan mitra 2 pelaksanaan pembuatan $\mathrm{POC}$ ini

dilakukan di balai desa Puger Kulon dengan waktu yang berbeda yaitu tanggal 23 dan 25 Juli 2017. Peserta sangat antusias mengikuti kegiatan pelatihan ini. Team pelatih tidak hanya mengajarkan bagaimana cara membuat pupuk organik cair dari limbah terasi, namun juga mengajarkan metode tanam dengan aqua ponik.

a. Mitra 1 yaitu perangkat desa Puger Kulon

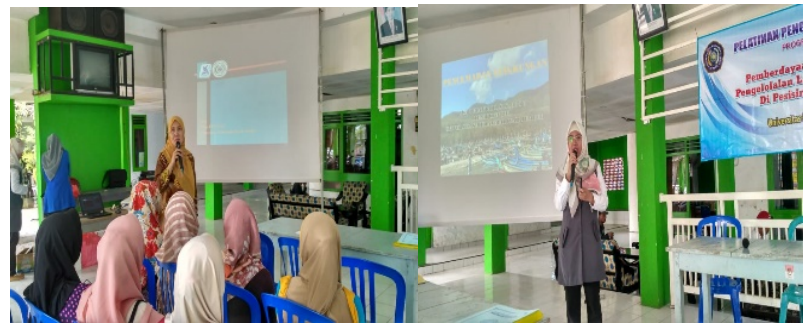

Figure 8. Pelatihan bersama dengan seluruh mitra 1 terutama perangkat desa b. Mitra 2 Pengelola terasi Puger

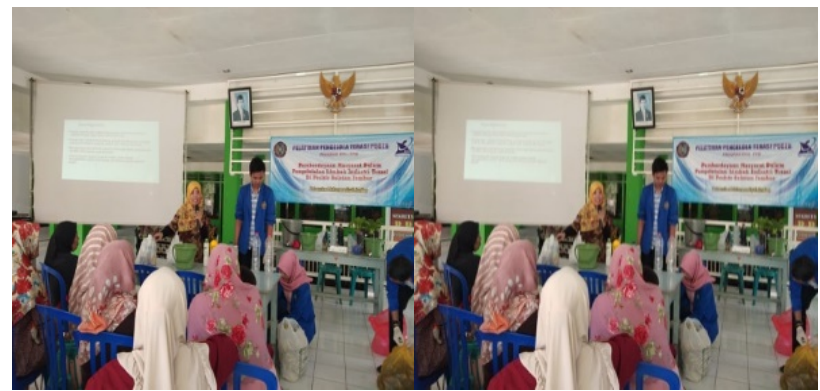

Figure 9. Pelatihan bersama dengan mitra 2 pengrajin terasi Puger

\subsubsection{Pembentukan kader Penghijauan}

Berkoordinasi dengan warga terutama di wilayah desa Gedangan Puger Kulon untuk mempersiapkan pembentukan kelompok kader penghijauan dan kelompok pengrajin terasi Puger. Daerah ini akan dicoba untuk dikembangkan menjadi percontohan kader penghijauan di Kelurahan Puger Kulon. Sasaran dari terbentuknya kader penghijauan adalah ibuibu yang ada di Gedangan serta Karang taruna. Masyarakat sangat antusias terbentuknya kader ini, yang akan memantau tanaman percontohan di wilayah Puger Kulon.

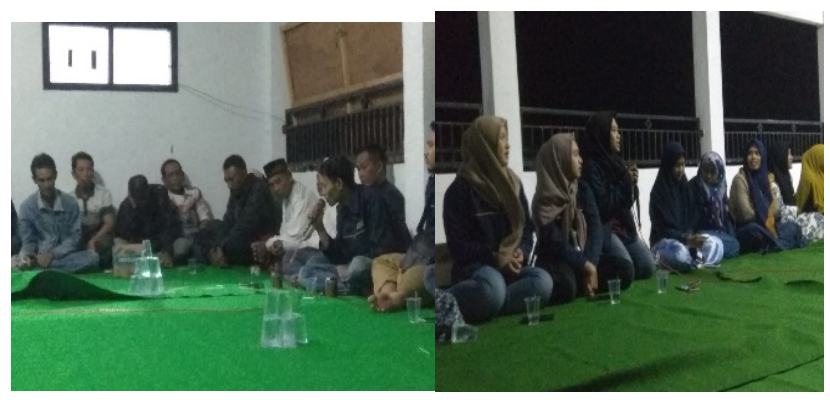

Figure 10. Rapat Koordinasi dengan karang taruna untuk pembentukan kader penghijauan

\subsubsection{Pelatihan teknik pemasaran}

Mitra 1 dan 2 diajarkan bagaimana mengemas terasi Puger menjadi produk unggulan yang menarik. Selain itu juga dapat memasarkan produk terasi dengan berbagai media pemasaran. Mitra sangat antusias mengikuti kegiatan tersebut, karena mereka selama ini hanya menjual produk dengan cara dititipkan di pasar. 


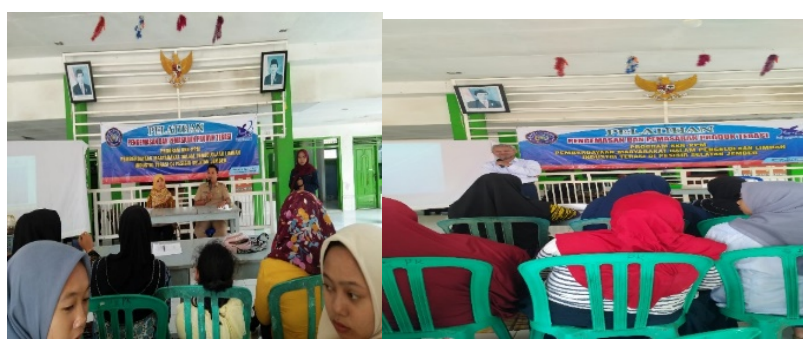

Figure 11. Pelatihan teknik pemasaran terasi Puger

\subsubsection{Pemberdayaan masyarakat dengan pemanfaatan pupuk organik cair}

Kegiatan ini merupakan kelanjutan dari terbentuknya kader penghijauan di Dusun Gedangan Puger Kulon. Ibu-ibu sangat antusias untuk menanam bibit cabai dan terong sebagai stimulan dalam pemanfaatan pupuk organik cair yang sudah dibuat.

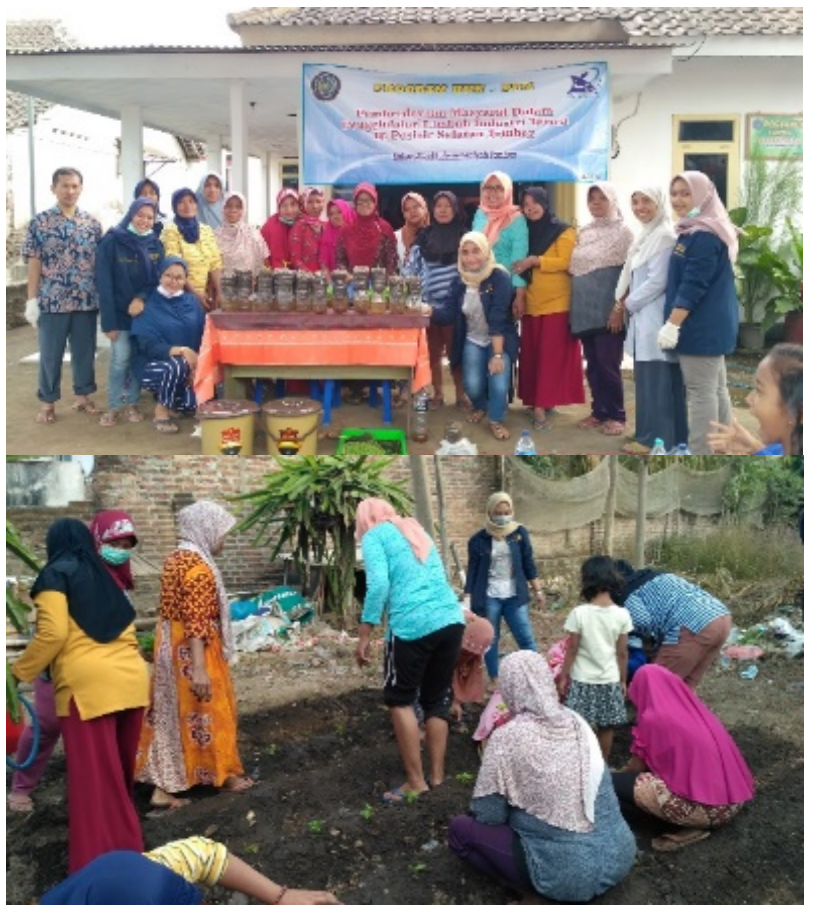

Figure 12. Pemberdayaan masyarakat tentang Penghijauan

\subsection{Pembahasan}

Limbah terasi merupakan limbah yang dapat dimanfaatkan untuk banyak kepentingan harian rumah tangga. Pada proses pembuatan pupuk organik cair dari limbah terasi ini menggunakan bioaktivator EM4. Fungsi dari Effective Microorganism4 (EM-4) digunakan untuk mempercepat dekomposisi sampah organik, selain itu EM-4 dan juga dapat meningkatkan pertumbuhan serta dapat meningkatkan kualitas dan kuantitas produksi tanaman.

\section{Kesimpulan}

\subsection{Kesimpulan}

a. Total volume kegiatan mahasiswa KKN PPM ini dalam bentuk Jam Kerja Efektif Mahasiswa (JKEM) yang dilakukan selama 2 bulan (24 Juli - 24 September 2019) dengan melibatkan 20 mahasiswa $=$ jumlah mahasiswa $(\mathrm{n}) \times$ total $\mathrm{JKEM}=20 \times 147$ $\mathrm{JKEM}=2.940 \mathrm{JKEM}$.

b. Indikator capaian produk Program KKN-PPM yang dituju adalah :

1) Peningkatan perilaku masyarakat tentang hidup bersih dan sehat

2) Peningkatan pemanfaatan limbah industry terasi menjadi pupuk organik cair

3) Peningkatan kemauan dan kemampuan masyarakat untuk melakukan penghijauan sekitar

4) Adanya partisipasi masyarakat dalam pertemuan kelompok pengrajin terasi $1 \mathrm{x}$ dalam tiap bulan

c. Pengelolaan Program KKN-PPM ini dalam jangka panjang akan dilanjutkan oleh LPPM Universitas Muhammadiyah Jember melalui kerja sama dengan Mitra (Pemerintah Desa Puger Kulon, Kecamatan Puger Kabupaten Jember) yaitu dengan menurunkan mahasiswa KKN pada lokasi yang sama dengan pendanaan dari Mitra, dan LPPM Universitas Muhammadiyah Jember serta mahasiswa dalam rangka pembinaan, monitoring dan evaluasi program.

d. Melibatkan masyarakat melalui kerja sama antar kelompok home industri terasi Puger, kerja sama antara kelompok home industri terasi Puger dengan Pemerintah kecamatan Puger Kabupaten Jember

e. Menambah Mitra lain, seperti PKK, Kader kesehatan dan Lembaga Ekonomi Mikro (Bank Perkreditan Rakyat), Dinas Koperasi dan UMKM, dalam rangka meningkatkan dan menguatkan ekonomi di lokasi kegiatan.

\subsection{Saran}

Perlu dilaksanakannya program jangka panjang untuk pengelolaan Program KKN-PPM 
yang dilanjutkan oleh LPPM Universitas Muhammadiyah Jember melalui kerja sama dengan Mitra (Pemerintah Desa Puger Kulon, Kecamatan Puger, Kabupaten Jember) yakni dengan menurunkan mahasiswa KKN pada lokasi yang sama dengan pendanaan dari Mitra, dan LPPM Universitas Muhammadiyah Jember serta mahasiswa dalam rangka pembinaan, monitoring dan evaluasi program.

Perlu menambah mitra lain seperti PKK, Kader kesehatan dan Lembaga Ekonomi Mikro (Bank Perkreditan Rakyat), Dinas Koperasi dan UMKM, dalam rangka meningkatkan dan menguatkan ekonomi di lokasi kegiatan.

\section{Ucapan Terima Kasih}

Tim Pelaksana KKN - PPM Universitas Muhammadiyah Jember mengucapkan terima kasih kepada Ditlitabmas DIKTI Jakarta atas bantuan dananya sehingga pelaksanaan KKN PPM tahun 2019 dapat berjalan dengan sangat baik

\section{Daftar Pustaka}

[1] Fananta et.all (2015), "Pemasaran Produk Terasi Hj. Ariyatun Khas Puger Kabupaten Jember.," eSOSPOL XXX, Jember.

[2] Gemaputri AA \& Anrosana A (2016), "Kelompok Usaha Terasi Puger.," jurnal Pengabdian Masyarakat J-DINAMIKA, Vol. 1, No. 1, Juni 2016, P-ISSN: 2503-1031, E-ISSN: 2503-1112, Jember.

[3] Giyarto (2004), "Sanitasi Industri dan Keamanan Pangan.," Jember: Fakultas Teknik, Jember .

[4] Hasanah N. \& Heryadi. (2012), "Potensi Pemanfaatan Limbah Udang Dalam Meningkatkan Pertumbuhan Tanaman Cabai.," Repository UT, Surabaya,.

[5] Majid A , Agustini TW, dan Rianingsih L. (2014), " Pengaruh Perbedaan Konsentrasi Garam Terhadap Mutu Sensori Dan Kandungan Senyawa Volatil Pada Terasi Ikan Teri (Stolephorus Sp).," Jurnal Pengolahan dan Bioteknologi Hasil Perikanan Volume 3, Nomer 2, Tahun 2.

[6] Ningrum PT. (2017) " Kondisi Sanitasi Tempat Pelelangan Ikan Dan Pengelolaan Limbah Di Wilayah Pesisir Puger Kabupaten Jember.," Prosiding Seminar Nasional Kelautan Dan Perikanan III 2017, Jember,

[7] Pemerintah Kabupaten.(2011), " Draft Rencana Tata Ruang Wilayah Kabupaten Jember Tahun 2011 2031.," Jember: Pemerintah Kabupaten. , Jember.

[8] Purtomo T, Ratih I. dan. Utomo DB (2016), "Ibm Kelompok Usaha Rumah Tangga Terasi Rebon Di
Lingkungan Pantai Teleng Kota Pacitan.," Jurnal Pengabdian LPPM Untag Surabaya Juli 201 6, Vol. 02, No. 01 , hal $19-28$.. 